\title{
2012 Whiteman Prize
}

JOSEPH WARREN DAUBEN received the 2012 AMS Albert Leon Whiteman Memorial Prize at the 118th Annual Meeting of the AMS in Boston in January 2012.

\section{Citation}

The American Mathematical Society is pleased to award the Albert Leon Whiteman Prize to Joseph

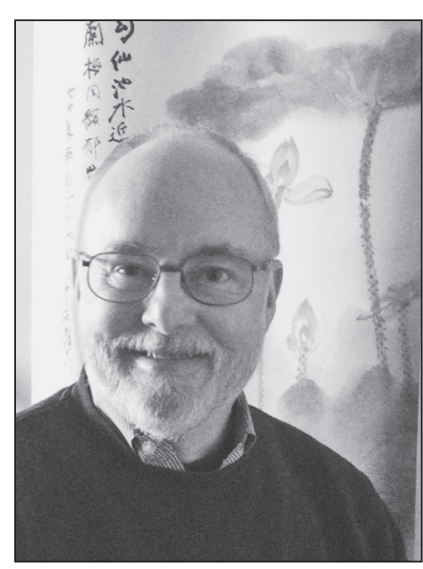

Warren Dauben for his contributions to the history of Western and Chinese mathematics and for deepening and broadening the international mathematical community's awareness and understanding of its history and culture. "In truth mathematics can be called the Pleasure Garden of the myriad forms, the Erudite Ocean of the Hundred Schools of Philosophy," said the sixteenth-century mathematician Xu Guangqi. Joe Dauben's work illuminates his epigram.

Dauben's first book, Georg Cantor: His Mathematics and the Philosophy of the Infinite (Harvard University Press, Cambridge, MA, 1979; reprinted, Princeton University Press, Princeton, 1990), is a clear, readable, detailed, richly textured history of Cantor's development of transfinite numbers and, at the same time, an insightful but nonreductive account of the complex and difficult personality that brought this revolution about. His second biography, Abraham Robinson: The Creation of Nonstandard Analysis, A Personal and Mathematical Odyssey (Princeton University Press, Princeton, 1995), is another near-impossible feat of scholarship and exposition. Dauben traces Robinson's nonstandard path from his birthplace in Germany to his death in New Haven, via Palestine, Paris, London, Toronto, Jerusalem, and Los Angeles, again intertwining the mathematician and his mathematics.

While writing Abraham Robinson, Dauben began a study of "Ten Classics of Ancient Chinese Mathematics", a $656 \mathrm{CE}$ edition of texts taught throughout Chinese history, in order to relate

DOI: http://dx.doi.org/10.1090/noti828 them to early Western mathematics and make them understandable to the modern reader. "Chinese mathematics," his contribution to The Mathematics of Egypt, Mesopotamia, China, India, and Islam (Princeton University Press, Princeton, 2007), is the fruit of twenty years of scholarship and, at nearly 200 pages, is a book in its own right. Dauben studies the history of modern Chinese mathematics as well; see, for example, his chapter "Modern science emerges in China" in Mathematics Unbound: The Evolution of an International Mathematical Research Community, 1800-1945 (History of Mathematics, 23, Karen Hunger Parshall and Adrian L. Rice, editors, American Mathematical Society, Providence, RI; London Mathematical Society, London, 2002). He is an elected Honorary Professor of the Institute for the History of Natural Science (a branch of the Chinese Academy of Sciences) and lectures there regularly.

In Writing the History of Mathematics: Its Historical Development (Sci. Networks Hist. Stud., 27, Birkhäuser, Basel, 2002), Dauben and coeditor Christoph Scriba engage historians of mathematics around the world to show how the practice of writing history of mathematics has varied from country to country and era to era and how this historiography is intertwined with the philosophical, scientific, and industrial demands of time and place. In the United States, the history of mathematics, once an excellent but eclectic collection of teaching tools and postretirement projects, has in the last decades become an integral component of the mathematical community, with well-attended sessions at major meetings. Joe Dauben has spurred this professionalism by his scholarly example and through his service to the profession, which includes organizing international workshops and symposia and editing Historia Mathematica for a decade.

Like his list of published articles, the list of Joe Dauben's honors is long. We are proud to add the Whiteman Prize to it.

\section{Biographical Sketch}

Joseph W. Dauben is Distinguished Professor of History and the History of Science at Herbert $\mathrm{H}$. Lehman College and a member of the Ph.D. Program 
in History at the Graduate Center of the City University of New York. He is a fellow of the New York Academy of Sciences, a membre effectif of the International Academy of History of Science, a corresponding member of the German Academy of Sciences Leopoldina, and a member of the Society of Fellows of the American Academy in Rome. He has been editor of Historia Mathematica, an international journal for the history of mathematics, and chairman of the International Commission on the History of Mathematics. He is the author of Georg Cantor, His Mathematics and Philosophy of the Infinite (Harvard University Press, Cambridge, MA, 1979; reprinted, Princeton University Press, Princeton, 1990) and Abraham Robinson: The Creation of Nonstandard Analysis, a Personal and Mathematical Odyssey (Princeton University Press, Princeton, 1995), both of which have been translated into Chinese. Among his most recent publications is the monographic study of one of the most ancient works of Chinese mathematics, "Suan shu shu. A book on numbers and computations. English translation with commentary" (Archive for History of Exact Sciences 62 (2008), no. 2, 91-178). A graduate of Claremont McKenna College, magna cum laude, in mathematics and of Harvard University (A.M. and Ph.D.) in history of science, Dauben has been a member of the Institute for Advanced Study (Princeton) and Clare Hall (Cambridge University), where he was affiliated with the Needham Research Institute. He has been the recipient of a Guggenheim Fellowship, Senior NEH and ACLS Fellowships, and was named Outstanding Teacher of the Year at Lehman College in 1986. He is an honorary member of the Institute for History of Natural Sciences of the Chinese Academy of Sciences, where he was the Zhu Kezhen Visiting Professor in spring of 2005. In 2010 he was Visiting Research Professor at the Institute for Humanities and Social Sciences at National ChiaoTung University in Hsinchu (Taiwan).

\section{Response from Joseph Warren Dauben}

Albert Leon Whiteman was a mathematician with a passion for number theory and an abiding interest in the history of mathematics. He was Hans Rademacher's first student at the University of Pennsylvania and a Benjamin Peirce instructor at Harvard before taking up a position in 1948 at the University of Southern California, where he spent the rest of his career. I might have been one of his graduate students, for USC was one of the universities where I was accepted to continue as a graduate student in mathematics after I had completed my undergraduate degree in 1966 at Claremont McKenna College in southern California. I had studied mathematics there with John Ferling, Granville Henry, and Janet Myhre and wrote my senior thesis, which later would prove to be especially useful, as it turned out, on nonstandard analysis. Ferling had himself been a student at USC and was the reason I had applied there as one of my choices for graduate school. But, having grown up in southern California, the offer Harvard made to pursue my doctorate there in history of science proved irresistible, and in the fall of 1966 I found myself on the East Coast, in Cambridge, where there was a lively, if small but in retrospect remarkable, concentration of historians of mathematics. The Department for History of Science, one of the first in the country, had just been established, and I was among the earliest groups to join the new department, along with my friend, colleague, and fellow historian of mathematics Wilbur Knorr. Wilbur and I were very fortunate to have been trained by, among others, John Murdoch and Judith Grabiner, who prepared us with tutorials for just the two of us for our oral examinations prior to working on our Ph.D.'s, which I did under the direction of Erwin Hiebert and Dirk Struik. While at Harvard, I was also fortunate to have worked with Richard Brauer, who took an interest in my thesis on Cantor and whose own memories of mathematics in Germany were always helpful to me in getting right the historical sense of the times in which Cantor had lived, especially his later years. If Brauer said something I had written sounded correct to him, I felt it must be pretty close to the mark. Later, another Harvard mathematician, Garrett Birkhoff, would likewise prove very helpful when the subject of my research turned to a biography of Abraham Robinson. Birkhoff had known Robinson and was interested in the historical implications of nonstandard analysis. Wim Luxumburg at Caltech and George Seligman at Yale were also colleagues and good friends of Robinson and likewise mathematicians to whom I am grateful for their reading of the history I was writing.

This is all by way of saying that, for historians of mathematics, our best audiences and most valuable collaborators are our mathematician colleagues. In the course of my career as a historian of mathematics, I have also learned the craft from many of my colleagues, who have been both inspirational and supportive. I was indeed fortunate to have several of what in Germany is called the Doktorvater, beginning with my mentor at Harvard, I. Bernard Cohen, whose own interest in history of mathematics included the work of Isaac Newton but also the great revolution in computers that led him to serve as IBM's chief historical consultant. That led to several summers when both Wilbur Knorr and I, among a number of graduate students, were employed to work for IBM on a massive history of computing database that Cohen was overseeing.

In Berlin, when I was there for a year doing archival research for my dissertation on Georg Cantor and the origins of transfinite set theory, Kurt R. Biermann, director of the Alexander von Humboldt 
Forschungsstelle at the Deutsche Akademie der Wissenschaften in what was then East Berlin, took me under his wing, as did Herbert Meschkowski at the Freie Universität and Christoph Scriba at the Technische Universität in West Berlin. The German circle of historians of mathematics kindly invited me to their annual meetings at the Mathematisches Forschungsinstitut at Oberwolfach in the Black Forest, where Joseph Ehrenfried Hofmann, especially known for his research on Leibniz, had established the Problemgeschichte der Mathematik seminars. Over the years meetings there with Christoph Scriba, Menso Folkerts, Ivo Schneider, Eberhard Knobloch, Herbert Mehrtens, among many others, introduced me to the grand tradition of history of mathematics in Germany. Later Christoph Scriba and I would codirect, with Hans Wussing and Jeanne Peiffer, a group project for the International Commission of the History of Mathematics that resulted in a collaborative historiographic study bringing colleagues from literally all parts of the world together to write a history of the discipline. Also among those to whom I owe so much, beginning with the help and encouragement he offered me as a graduate student, is Ivor Grattan-Guinness, whose own early work on Georg Cantor proved extremely helpful to me, especially through the strategic suggestions Ivor was willing to offer at the time to a fledgling graduate student; but over the years since, his critical and editorial eye has always been welcome, as well as the various projects on which we have worked together.

In fact, throughout my career, working with mathematicians and historians in different parts of the world has been the most rewarding and inspirational aspect of collaborative research. This has certainly been true of the undertaking I began nearly twenty-five years ago, in 1988, when I was invited to spend six months in China under a program jointly sponsored by the Chinese Academy of Sciences and the U.S. National Academy of Sciences. I spent several months that spring in Beijing at the Institute for History of Natural Sciences, where I joined the seminar on history of Chinese mathematics being taught by Du Shiran. It was there that I met Guo Shuchun and Liu Dun, two historians of mathematics who, along with Lam Lay Yong in Singapore and Horng Wann-Sheng in Taiwan, have also been those from whom I have learned the history of Chinese mathematics. Wann-Sheng, in fact, not long after I returned to New York from Beijing, was the first of my Chinese graduate students, and the other joy of teaching is the opportunity it provides for working with especially able students. Although I have not had many graduate students, those with whom I have worked have been a pleasure to mentor, and in the process, I am convinced that I learn as much from them as I hope they have learned from working with me. The first student to find his way to New
York for a second doctorate in history of science after having already completed a Ph.D. in mathematics was David Rowe, then Horng Wann- Sheng, and most recently, Xu Yibao. At the moment, I have yet another graduate student from Taiwan, Chang Ping-Ying, who is working on a history of the Suanxue (College of Mathematics) in the Qintianjian (Bureau of Astronomy) in the early Qing Dynasty, a reminder of the fact that in virtually all cultures in all parts of the world, mathematicians have significant roles to play, not just in the advancement of the theoretical understanding of the subject but in a wide variety of applications.

In addition to the very great extent to which the American Mathematical Society and the Mathematical Association of America have furthered the history of mathematics through the invited sessions on history, which usually run a full two days at the annual joint meetings (for which over the years I've served as co-organizer with, at various times, David Zitarelli, Karen Parshall, Victor Katz, Patti Hunter, and Deborah Kent), the History of Science Society in recent years has also shown increasing interest in the history of mathematics. There Karen Parshall and Albert Lewis have been instrumental, along with support offered by Harry Lucas, in establishing a Forum of the History of Mathematics that we hope will serve to increase further the prominence of history of mathematics at HSS annual meetings.

In retrospect, I have much to be thankful for in a career that has brought me into touch with mathematicians and historians the world over, many of whom I consider not just colleagues but good friends, including the students I have been privileged to have at the Graduate Center of the City University of New York. But it is my home institution, Herbert H. Lehman College, to which I must say a special thank you for the resources and encouragement it gives to faculty, especially for their research and participation in conferences and projects involving the larger academic community of scholars. It was Lehman that gave financial support and released time from teaching when Esther Phillips and I served as editors of Historia Mathematica following the sudden and unexpected death of its founding editor, Kenneth $\mathrm{O}$. May. More recently, Lehman helped make possible a year at the Research Center for Humanities and Social Sciences at National Chiao-Tung University in Hsinchu, Taiwan. There, with few obligations apart from my own research, I spent all of 2010 completing a translation with critical commentary of the Nine Chapters on the Art of Mathematics (one of the Ten Classics of Ancient Mathematics). The Nine Chapters, including its commentaries, is the compendium of mathematics from ancient China on which I have been fortunate to work with my colleagues Guo Shuchun in Beijing and Xu Yibao in New York. This collaborative effort would not 
have been possible were it not for the joint support of the City University of New York, Chiao-Tung University in Taiwan, and the Institute for History of Natural Sciences in Beijing.

What sets the history of mathematics apart from the history of science generally is that it is not an arcane history about past theories that have been discarded, forgotten as failed attempts to understand the workings of nature, but instead the history of mathematics is a living history. In the nineteenth century Weierstrass recommended that his students read the classics of the past, for such works might well contain ideas and methods that could still prove useful, even inspirational, to current mathematical research on the frontiers of the subject. It is for this reason that mathematicians, more than any other practitioners among the sciences, have a very real interest in their history-not just to remember the past, but to use it. For the tangible support and visibility that awards like the Whiteman Memorial Prize provide for the subject, historians of mathematics can truly be grateful, and at this moment in particular, none more than I. To the AMS Council and to the members of the selection committee, I want to express my sincere appreciation, and on behalf of historians of mathematics everywhere, my heartfelt thanks as well to Mrs. Sally Whiteman for establishing this outstanding memorial for her husband, Albert Leon Whiteman.

\section{About the Prize}

The Whiteman Prize is awarded every three years to recognize notable exposition and exceptional scholarship in the history of mathematics. The prize was established in 1998 using funds donated by Mrs. Sally Whiteman in memory of her husband, the late Albert Leon Whiteman. The prize carries a cash award of US\$5,000.

The Whiteman Prize is awarded by the AMS Council acting on the recommendation of a selection committee. For the 2012 prize, the members of the selection committee were Robin Hartshorne, Marjorie Senechal, and William C. Waterhouse. Previous recipients of the Whiteman Prize are Thomas Hawkins (2001), Harold M. Edwards (2005), and Jeremy J. Gray (2009).

- Elaine Kehoe

\section{Award for Distinguished Public Service}

WILLIAM MCCALLUM received the 2012 Award for Distinguished Public Service at the 118th Annual Meeting of the AMS in Boston in January 2012.

\section{Citation}

William McCallum is University Distinguished Professor and Head of the Mathematics Department at the University of Arizona. In recent years, McCallum has shown extraordinary energy in promoting improvement of mathematics education, and he has been almost ubiquitous in organizations devoted to mathematics education. He has served as chair of the Committee on Education of the AMS and as chair of CBMS. He is a member of the International Design Committee for the Klein Project, an effort of the International Commission on Mathematics Instruction and the International Mathematical Union to produce a set of narratives or "vignettes" about contemporary mathematics to educate and inspire today's high school teachers in the way that Felix Klein's lectures and books on "Elementary Mathematics from an Advanced Standpoint" did 100 years ago. He has also been

DOI: http://dx.doi.org/10.1090/noti822
Principal Investigator on a Mathematics and Science Partnership grant.

However, his most significant recent activities have also been the most distinctive. He is the founding Director of the Institute for Mathematics and Education (IME) at the University of Arizona and is currently director of its Advisory Committee. This Institute was founded explicitly on the principle that to deal effectively with issues of mathematics education requires communication and cooperation among teachers, mathematics education researchers, and mathematicians. In dozens of events over the past five years, many people from all three groups have met for mutually productive activities under the auspices of IME.

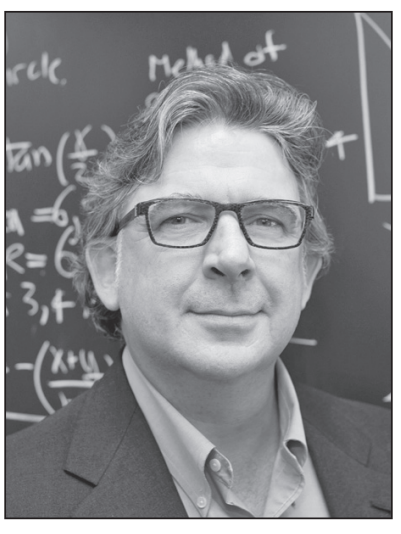

William McCallum
Mostrecently, hewas onemember of the three-person writing team selected by the Council of Chief State School Officers and the National Governors Association to orchestrate and execute the production of the Common Core State Math- 